\title{
Restricted Prioritarianism or Competing Claims?
}

\author{
Benjamin Lange \\ Lady Margaret Hall, Oxford
}

\begin{abstract}
I here settle a recent dispute between two rival theories in distributive ethics: $R e^{-}$ stricted Prioritarianism and the Competing Claims View. Both views mandate that the distribution of benefits and burdens between individuals should be justifiable to each affected party in a way that depends on the strength of each individual's separately assessed claim to receive a benefit. However, they disagree about what elements constitute the strength of those individuals' claims. According to restricted prioritarianism, the strength of a claim is determined in 'prioritarian' fashion by both what she stands to gain and her absolute level of well-being, while, according to the competing claims view, the strength of a claim is also partly determined by her level of well-being relative to others with conflicting interests. I argue that, suitably modified, the competing claims view is more plausible than restricted prioritarianism.
\end{abstract}

\section{Introduction}

We can distinguish between two morally significant facts." According to what we can call the

Unity of the Individual, an individual's life has a unity that renders it appropriate to balance benefits and burdens which accrue to her for her sake (in a way that maximizes her expected well-being ${ }^{1}$ ) but inappropriate to balance benefits and burdens which accrue to her as if they accrued to different individuals' lives; ${ }^{2}$

* I am grateful to David Healey, Geoff Keeling, Will MacAskill, James Matharu, and an anonymous referee for feedback on earlier drafts of this paper. I am especially indebted to Mike Otsuka and Alex Voorhoeve for extensive comments and discussion.

${ }^{1}$ I will here be mainly concerned with health-related well-being. Moreover, henceforth the term 'wellbeing' should be understood synonymously with 'utility', where both stand for how well an individual's life is going or would go.

${ }^{2}$ When speaking of the prospective gains (benefits) in well-being throughout this paper, I shall assume a cardinal, interpersonally comparable preference-based measure of well-being that satisfies the von Neumann- 
And according to the

Separateness of Persons, a group of individuals' lives have a separateness that renders it inappropriate to balance benefits and burdens which accrue to them as if they accrued to a single life. $^{3}$

Recently, two views have been proposed which register this difference: Restricted Prioritarianism, proposed by Andrew Williams, and the Competing Claims View, proposed by Marc Fleurbaey, Michael Otsuka, and Alex Voorhoeve. ${ }^{4}$

Both views mandate that the distribution of benefits and burdens between individuals should be justifiable to each affected party in a way that depends on the strength of each individual's separately assessed claim to receive a benefit. However, they disagree about what elements constitute the strength of those individuals' claims. According to restricted prioritarianism, the strength of a claim is determined in 'prioritarian' fashion by both what she stands to gain and her absolute level of well-being (with a claim to a given increment in well-being being stronger, the lower the level from which this increment takes place), but her claim is unaffected by how others fare. According to the competing claims view, the strength of a claim is also partly determined by her level of well-being relative to others with conflicting interests.

\footnotetext{
Morgenstern axioms. This measure is based on the 'self-interested preferences that [an] individual would have after ideal deliberation while thinking clearly with full pertinent information regarding those preferences' (Richard Arneson, 'Primary Goods Reconsidered', Noûs 24 (1990), pp. 429-54, at p. 448). See also Michael Otsuka and Alex Voorhoeve, 'Why It Matters That Some Are Worse Off Than Others: An Argument against the Priority View', Philosophy and Public Affairs 37 (2009), pp. 171-99, at pp. 172-73, n. 3. As Otsuka and Voorhoeve point out, note that endorsing this measure does not commit one to any particular view of what well-being $i$.

${ }^{3}$ I am presupposing the moral significance of the contrast between the unity of the individual and the separateness of persons for this discussion. Some appear to disagree with this significance. For example, Iwao Hirose, 'Aggregation and the Separateness of Persons', Utilitas, 25 (2013), pp. 182-205, appears to find the separateness of persons an unilluminating concept if it doesn't rule out interpersonal aggregation and implausible if it does. In contrast with Hirose, I take it the value of the concept lies in that it rules out particular forms of utilitymaximizing calculus that would be appropriate within the bounds of an individual's life.

${ }^{4}$ See Andrew Williams, 'The Priority View Bites the Dust?', Utilitas 24 (2012), pp. 315-31; Alex Voorhoeve and Marc Fleurbaey, 'Egalitarianism and the Separateness of Persons', Utilitas 24 (2012), pp. 38198; and Otsuka and Voorhoeve, 'Why It Matters', pp. 171-99. Note: I have modified the name of Williams' view slightly to make it more informative. In his own paper, Williams uses the name 'Restricted View'. I also use 'the Priority View' and 'prioritarianism' interchangeably throughout.
} 
My aim in this paper is to settle this dispute. I advance two main claims: First, I argue that, suitably modified, the competing claims view is more plausible than restricted prioritarianism. And second, I argue that insofar as the competing claims view escapes the force of the Levelling Down Objection, the onus is on the prioritarian defender to tell us why we should endorse restricted prioritarianism in the first place.

This paper proceeds as follows. In Section 2, I formulate the restricted- and competing claims view. In Section 3, I show that restricted prioritarianism is unable to capture some morally significant justifications of arrangements to the individuals involved. In Section 4, I argue that, while the Competing Claims View runs into the same problem as restricted prioritarianism, unlike the latter, it is open to modification. I then consider two possible modifications: a new Claim Egalitarian View and a Modified Competing Claims View. I argue that the latter is the most plausible, because it a) correctly captures the cases that its counterparts cannot and $b$ ) avoids the Levelling Down Objection in a plausible manner. Section 5 concludes.

\section{Two Similar But Importantly Different Views}

In his essay 'The Priority View Bites the Dust?', Andrew Williams develops an alternative version of prioritarianism. This version aims to justify the distribution of benefits and burdens to affected parties via the assessment of the strength of each individual's claim to be helped. ${ }^{5}$ On what we can call

Restricted Prioritarianism, an individual has a claim to receive a benefit if and only if her well-being is at stake; the strength of her claim is determined by

i) her potential gain in well-being; and

5 'The Priority View Bites the Dust?', pp. 315-33. 
ii) the absolute level from which this gain takes place (with a claim to a given increment in well-being being stronger, the lower the level from which this increment takes place); but

iii) her claim is unaffected by how her level of well-being compares to others' level of well-being. ${ }^{6}$

Crucially, pioritarians claim that we have stronger reasons to benefit individuals the worse off they are in absolute terms, because each individual's utility has diminishing marginal moral importance. In contradistinction to egalitarians, they claim that such reasons do not depend on the fact that individuals are worse off than others. ${ }^{7}$

The scope of restricted prioritarianism is limited to interpersonal conflicts of interest. While Williams grants that in intrapersonal conflicts under risk individuals might have a claim that 'conflicts are resolved in a way that maximizes their expected utility, assuming individuals' preferences and utility coincide's, he believes that such claims could only arise on prudential and not moral grounds. So, in this sense the view is restricted, since its prioritarian weightings are only triggered in interpersonal conflicts.

Williams provides a plausible interpretation for his view by drawing on the work of Thomas Nagel. As he points out, Nagel himself stresses the dissimilarity of conflicts within as opposed to across lives throughout his own writing. For example, in The Possibility of Altruism, Nagel argues that the unity of the individual and the separateness of persons each favour different principles in cases of intra- and interpersonal conflict resolution. In support of this, Nagel writes:

${ }^{6}$ All of the claims-based views that I will be considering can also potentially accommodate different forms of aggregation. For this see Alex Voorhoeve, 'How Should We Aggregate Competing Claims?', Ethics 125 (2014), pp. 64-87.

7 See Derek Parfit, 'Equality and Priority', Ratio 10 (1997), pp. 202-221, at pp. 212-15.

8 'The Priority View Bites the Dust?', p. 323. 
when we are presented with several conflicting reasons stemming from the interests of another person, we must weigh them against one another by the same principles which it would be rational for that individual to employ in weighing the subjective reasons from which they originate $[\ldots]$ It does not follow, however, that I can apply this same function to a collection of reasons stemming from both our interests, or from his interests and those of someone else. It appears in fact unlikely that the objective versions of even sophisticated intrapersonal combinatorial principles can be applied to interpersonal problems. ${ }^{9}$

More generally, when he characterizes his own approach to distributive ethics, Nagel says quite explicitly that his view concerns 'how to settle conflicts among the interests of different people', and introduces pairwise comparisons as 'the natural way to deal with conflicting claims'. ${ }^{10}$ In light of these remarks, Williams concludes that there is plausible support for the restricted reading of the priority view, which is thus not merely an ad hoc move.

Restricted prioritarianism has a rival relational counterpart, which also lays claim to support from Nagel's work. On what Fleurbaey, Otsuka and Voorhoeve call the

Competing Claims View, an individual has a claim to receive a benefit if and only if her well-being is at stake; the strength of her claim is determined by

i) her potential gain in well-being; and

ii) her level of well-being relative to others with whom her interests conflict.

Unlike restricted prioritarianism, the competing claims view is not only limited to interpersonal conflicts. Rather, it grounds the moral claims of individuals also on their prudential (welfare-based) interests. For example, as Voorhoeve and Fleurbaey write, in a pure in-

\footnotetext{
${ }^{9}$ See Thomas Nagel, The Possibility of Altruism (Princeton, 1970), p. 134. (Also quoted in 'The Priority View Bites the Dust?', p. 326.)

10 See Thomas Nagel, 'Equality', Mortal Questions (Cambridge, 1979), pp. 55-65, reprinted in The Ideal of Equality, ed. Clayton and Williams (Basingstoke, 2002); and Thomas Nagel, Equality and Partiality (New York, 1991), pp. 64-78.
} 
trapersonal, one-person case under risk, this amounts to a claim 'to be exposed to a sufficiently attractive gamble'11_ a gamble which maximizes the person's expected well-being.

More importantly for us, the competing claims view differs from restricted prioritarianism in a second respect. While restricted prioritarianism grounds the claims of individuals in part on their absolute levels of well-being, the competing claims view grounds them on the relative difference between individuals with claims. It is thus relational view.

But unlike most egalitarian views, the competing claims view is of a Nagelian sort, which gives comparative advantage its due by appealing to the notion of justifiability to each affected party:

How, one might ask rhetorically, can one justify providing a benefit of a given size to someone who is already better off in order to make him better off still, when one could instead provide an equally large benefit to someone else who is worse off, and who would not even reach the (unimproved) level of the better off person if she (the worse off person) is benefited?12

So, both Williams as well as Otsuka, Voorhoeve and Fleurbaey draw on Nagel to justify the plausibility of their respective views. This might prompt us to ask which interpretation is correct. Although this question lies beyond what I intend to cover here, my tentative answer would probably be 'both'. In his own writings on egalitarianism, Nagel never clearly distinguishes between non-relational and relational ways of giving priority to the worst off. This makes it difficult to decide which side he favours.

Both views also correctly register the difference between the unity of the individual and the separateness of persons. They grant that an individual has a claim to have her potential benefits and burdens balanced from the perspective of her interest in intrapersonal trade-off cases.

11 'Egalitarianism and the Separateness of Persons', p. 397.

12 'Why It Matters', pp. 183-84. 
A morally motivated stranger who has to decide on behalf of that individual might then satisfy her claim provided that her expected potential benefit is sufficiently large to outweigh her expected burden - the important difference being that a defender of restricted prioritarianism would argue that these would be prudential and, unlike a proponent of the competing claims view, not moral reasons. ${ }^{13}$

In interpersonal trade-off cases, in which individuals' claims compete because they cannot be jointly met, both views agree on satisfying the strongest claim after considering how much individual stands to gain and either each individuals a) absolute level of well-being or b) wellbeing relative to other individuals who also have a claim. It thus seems that insofar as both views are correctly sensitive to the difference between the unity of the individual and separateness of person, they are equally plausible.

The following sections attempt to change this picture.

\section{A Problem for Restricted Prioritarianism?}

When trying to decide between two competing theories, we can say theory $A$ is less plausible than theory $B$ if $A$ fails to capture morally significant facts while $B$ does not, all other things being equal. In such a case, theory $A$ lacks the explanatory power of theory $B$, which gives us reason to endorse $B$. The first part of my argument follows this dialectic. I here show that restricted prioritarianism cannot capture some morally significant justifications of arrangements to the individuals involved. To illustrate this challenge, consider the following case:

\footnotetext{
13 There are two reasons for this: First, as we noted, according to restricted prioritarianism's Nagelian rationale, it applies only to interpersonal conflicts. Second, if a proponent of restricted prioritarianism claimed that there could be prioritarian moral reasons to benefit absolutely worse off individuals in intrapersonal cases, then this would expose restricted prioritarianism to a separateness-of-persons-based objection. For this see Otsuka and Voorhoeve, 'Why It Matters', pp. 179-81; and Michael Otsuka, 'Prioritarianism and the Separateness of Persons', Utilitas 24 (2012), pp. 365-80.
} 
Twin Trouble. Imagine you are a soon-to-be parent who will have either of two sets of twins. Either Anne and Betty or Chloe and Daisy will be born. Suppose that the existence of the two pairs is equally likely. You have just received bad news from your doctor: your children are certain to develop different impairments in the case that they are born. If Anne and Betty are born, Anne will develop a moderate respiratory impairment and Betty, being quite unlucky, will develop a very severe impairment. If Chloe and Daisy are born, Chloe will develop a moderate mobility impairment, comparable in severity to Anne's, but Daisy will be fine. You need to change jobs and must therefore now decide whether you will move to the coast or the countryside. If you move to the coast, Anne could receive treatment in a special medical facility which would somewhat alleviate the effects of her disability. However, there would be no special facilities to treat Betty who suffers from a very rare and incurable impairment. Neither would Chloe nor Daisy be able to benefit from the move to the coast. Alternatively, you could also move to the mountain region where Chloe would have access to a unique medical facility which would also somewhat alleviate the effects of her mobility impairment. But again, neither Daisy nor Anne and Betty would benefit from the move to the countryside. Suppose that the benefit to Anne by moving to the coast would be as great as the benefit to Chloe by moving to the countryside. How should you choose?

Table 1 represents the above case. $S_{1}$ and $S_{2}$ are equiprobable states of the world. An empty cell represents non-existence. As noted before, to make a discussion of the prioritarian view possible I shall assume a cardinal, interpersonally comparable measure of utility (see n. 2) where a utility level of 0 corresponds to a quality of life barely worth living, while a utility level of 1.0 corresponds to full health. The utilities described correspond to the respective impairments of the four twins. Lastly, I assume that none of them have claims based on desert or 
prior entitlements, and that they enjoy their respective level of well-being through no choice or fault of their own.

Table 1. Utilities for Twin Trouble.

\begin{tabular}{|c|c|cc|}
\hline & \multicolumn{2}{|c|}{ State of the world (equiprobable) } \\
\hline & \multicolumn{2}{|c|}{$S_{1}(50 \%)$} & $S_{2}(50 \%)$ \\
\hline Individuals & Anne \& Betty Chloe \& Daisy & Anne \& Betty & Chloe \& Daisy \\
\cline { 1 - 1 } $\begin{array}{c}\text { Move to } \\
\text { Coast }\end{array}$ & $0.7,0.2$ & $0.5,1$ \\
\cline { 1 - 2 } $\begin{array}{c}\text { Move to } \\
\text { Countryside }\end{array}$ & $0.5,0.2$ & $0.7,1$ \\
\hline
\end{tabular}

The set-up of the case relatively simple: we can either choose to move to the coast which improves Anne's quality of life in case she and Betty exist, or we can choose to move to the countryside which would equally improve Chloe's quality of life in case she and Daisy exist. If we choose to move to the coast but $S_{2}$ comes about, Chloe will not be able to receive the treatment for her disability, and vice versa for Anne if we choose the countryside but $S_{l}$ obtains. Note that the levels of well-being of Anne and Chloe are the same if they each fail to receive a benefit and equal if they each receive a benefit, and hence their potential increments in utility improvement are also identical.

$S_{1}$ and $S_{2}$ differ only in one important respect: in $S_{2}$, Chloe and Daisy will exist and Daisy will have a higher level of well-being than Chloe; and in $S_{1}$, Anne and Betty will exist and Betty will have a lower level of well-being than Anne. Given that $S_{1}$ and $S_{2}$ are equally likely to occur and Chloe would fare relatively worse than Daisy while Anne would fare relatively better than Betty, it seems correct that we should move to the countryside in order to help Chloe.

How would Williams' restricted view rule in this case? To answer this question, we first need to determine who of the four twins has a claim to on our assistance. Since claims can be made 
only on behalf of 'affected parties' 14 or individuals who could benefit from our actions, there is no claim on behalf of Betty or Daisy. They remain unaffected by our actions. On the other hand, because Anne and Chloe could potentially from the move to the cost or the countryside and receive treatment for their disability, each of them has a claim.

Now, since we must choose between moving either to the coast or the countryside but cannot choose both, Anne's and Chloe's claims are in competition with each other. This means that we have to assess the strength of their individual claims in order determine whose claim to satisfy.

At this point, one might question whether claims of merely possible people have any moral weight. I believe it is plausible to assume that they do here, because Anne and Betty have a positive chance of existing that is independent of our actions and we, as their guardian, have to take action. ${ }^{15}$ As opposed to some so-called non-identity cases, our actions here do not affect the identities of the people who will come to exist. If it is certain that some individuals will exist independently and that, depending on how we act now, we would influence their level of their well-being in case they existed, then I believe we also ought to look after how they would fare.

With this aside, now suppose that we move to countryside but $S_{1}$ comes about. Knowing that she could have also received treatment for her disability, Anne would probably complain and ask why we did not choose to help her. We could then provide her with the following justification for our decision:

We had stronger reasons to move to the countryside, because, if Chloe had existed, she would have been worse off than Daisy even after having received the treatment for her disa-

14 'The Priority View Bites the Dust?', p. 322 and p. 324.

15 Note that it here also matters that Anne and Betty have an equal chance of existing. It matters because it affects how much weight one ought to assign to their claims. See also 'Prioritarianism and the Separateness of Persons', p. 372-73. 
bility. In your case, you are now still better off than Betty. Since there was a 50:50 chance that you or Chloe would exist, have the same level of well-being and face the same increment in well-being improvement, Chloe's claim was strengthened by the fact that she would fare less well than Daisy. We therefore chose to move to the countryside.

Restricted prioritarianism cannot give the above justification. Since it determines the strength of an individual's claim by considering her absolute level of well-being, it is indifferent as to whether we choose to move to the coast or the countryside. On a cardinal interpersonal measure of well-being, which the prioritarian must presuppose, Anne's and Chloe's levels are identical in absolute terms, which means that they are equally badly off. It therefore follows on restricted prioritarianism that, ceteris paribus, their claims to receive the benefit must be equally strong. In this case, then, restricted prioritarianism cannot capture the conviction that we should help Chloe.

I concede that a prioritarian defender might find the above hardly surprising. She could resist and argue as follows: The reason why restricted prioritarianism is unable to track our conviction that we have stronger reason to choose to move to the countryside for Chloe is because it is a non-relational theory. It contrasts with a relational theory, which might determine the strength of a claim based on the level of well-being of an individual relative to other individuals. Our reason to help Chloe stems from our consideration of her fate in relation to Daisy's which is much better than hers. It is therefore not surprising that restricted prioritarianism is insensitive to this consideration.

Nonetheless, this can hardly excuse the fact that restricted prioritarianism is indifferent about Twin Trouble. A diagnosis of a theory's explanatory defect is no defence of that theory. In order to stay true to her commitment to non-relationality, a prioritarian defender here either 
has to tell us why our intuitions might be misplaced, or bite the bullet. In any case, this leaves her view unable to respond to the argument I have advanced here and therefore casts doubt on restricted prioritarianism's plausibility.

\section{Do the Twins Cause Less Trouble For the Competing Claims View?}

\subsection{On the Plausibility of a Claim Egalitarian View}

How does the competing claims view do in the Twin Trouble case?

Although the competing claims view is a relational theory, it also struggles with Twin Trouble. Because it, like its prioritarian counterpart, assumes that an individual has a claim just in case she has her interest at stake, only Anne and Chloe have a claim on our assistance. And insofar as each of them stands to individually gain equal utility improvements through the treatment of their disability, their claims must be equally strong.

What about their respective levels of well-being? As we have seen previously, according to Voorhoeve and Fleurbaey, only the inequality in well-being between individuals with conflicting interests affects the strength of those individuals' claims. ${ }^{16}$ To illustrate this, note that, for example, Betty and Daisy do not have conflicting interests, because they could not benefit from the move to the coast or the countryside. Neither option is in their interest, because neither option would improve their health-related level of well-being.

By contrast, the situation changes when we consider Anne and Chloe. It is certainly in Anne's interest that we choose to move to the coast, while it is in Betty's that we choose to move to the countryside; their interests $d o$ conflict. This means that the hypothetical difference between only Anne and Chloe's level of well-being is relevant in determining the strength of their claims.

\footnotetext{
16 'Egalitarianism and the Separateness of Persons', p. 397.
} 
However, there is no difference between the level of well-being from which the potential improvement to which they have a claim takes place. The competing claims view must therefore conclude that both have equally strong claims. This is surprising, since one would have thought that a view aiming to track relativities among individuals should be able to capture what is at stake here, unlike its non-relational competitor.

The reason why the competing claims view struggles with Twin Trouble is that it is solely concerned with the inequality between individuals whose interests conflict. Fleurbaey, Otsuka and Voorhoeve do not explain why only inequality of this kind should be relevant in determining the strength of an individual's claim. I suspect the reason is that by limiting the inequality to individuals with conflicting interests, they do not have to invoke the intrinsic badness of unfair inequality. But it is precisely this commitment that prevents the competing claims view from capturing Twin Trouble.

As a consequence, we might therefore modify the competing claims view in the spirit of theories as developed by G.A Cohen and Larry Temkin, which are primarily concerned with unchosen and undeserved outcome inequality. ${ }^{17}$ Temkin argues for the moral significance of the fact that some people are worse off than others through no choice or fault of theirs:

Equality is a subtopic of the more general $[\ldots]$ topic of fairness. Specifically, concern about inequality is that portion of our concern about fairness that focuses on how people fare relative to others. [...] We say that inequalities are objectionable because they are unfair; but by the same token, we say that there is a kind of unfairness in being worse off than another through no fault or choice of one's own. ${ }^{18}$

17 See G. A. Cohen, 'On the Currency of Egalitarian Justice', Ethics (1989), pp. 906-44; and Larry S. Temkin, 'Inequality: A Complex, Individualistic, and Comparative Notion', Philosophical Issues 11 (2001), pp. 327-53, and 'Equality, Priority, and the Levelling Down Objection', The Ideal of Equality, ed. Clayton and Williams (Basingstoke, 2002), pp. 126-61.

18 'Inequality', p. 334. 
Given these remarks, perhaps the most obvious move is to extend the concern about comparative fairness in contemporary relational egalitarian theories also to the competing claims view. On what we can then call the

Claim Egalitarian View, the strength of an individual's claim depends in part on her level of well-being relative to others who might be unfairly worse or better off than her.

The view can now correctly rule that Chloe's claim is stronger than Anne's, because she is unfairly worse off than Daisy.

Although this solves our problem, it comes at a certain cost. Derek Parfit has challenged egalitarian views that invoke the intrinsic badness of inequality and argued that such views are vulnerable to the LDO. ${ }^{19}$ His challenge has since then become perhaps 'the most prevalent and powerful anti-egalitarian argument'. ${ }^{20}$ It has led some to ultimately abandon relational egalitarianism and to opt for prioritarian or other approaches that do not appeal to the intrinsic badness of equality. ${ }^{21}$

The LDO's force consists in the observation that a commitment to the intrinsic badness of inequality implausibly implies that it is at least in one respect better if we eliminate inequality by making some people worse off and no one better off. As Parfit poignantly puts it, this amounts to destroying 'the eyes of the sighted, not to benefit the blind, but only to make the sighted blind'. ${ }^{22}$ But most people believe that there is nothing good about such a levelling down case. Accordingly, they conclude, a view which has this implausible implication, should be rejected.

19 'Equality and Priority', pp. 210-14.

20 'Equality, Priority, and the Levelling Down Objection', p. 126.

${ }^{21}$ See Richard Arneson, 'Egalitarianism and Responsibility', The Fournal of Ethics (1999), pp. 232-33.

22 'Equality and Priority', p. 211. 
It seems difficult to see how the claim egalitarian view could avoid this implication. Since its proponents believe that inequality is intrinsically bad and that its elimination gives us moral reason to satisfy one claim over another, it seems that they should also maintain that it is in one respect better if we made some people worse off and no one better off.

In response, we might suggest that our moral reasons to make things more equal are triggered only when, and because, doing so meets an individual's claim. Frances Kamm captures something reminiscent of this idea with her Principle of Contextual Interaction, according to which some properties might have no weight in some contexts, but still have weight in others. ${ }^{23}$ Another example can be found in Jonathan Dancy's work, who proposes a distinction between socalled favourers and enablers for different forms of relevance of relevant considerations. ${ }^{24}$ I quote:

There is a general distinction between a feature that plays a certain role and a feature whose presence or absence is required for the first feature to play its role, but which does not play that role itself. The distinction between favouring and enabling is a special case of this general distinction. ${ }^{25}$

If Dancy's analysis is correct, then we might entertain the hypothesis that our moral reasons to act on inequality are triggered only in case we thereby promote an individual's claim. The favourer of the elimination of unfair inequality accordingly requires the presence of an individual's claim as an enabler. If an individual's claim is absent, our reasons to decrease inequality by levelling-down are consequently disabled. ${ }^{26}$

There are other examples for normative reasons for action. I might promise my friend to do $X$, which speaks in favour of or gives me reason to do $X$. If this is the only relevant considera-

\footnotetext{
${ }^{23}$ See Frances Kamm, Intricate Ethics: Rights, Responsibilities, and Permissible Harm (Oxford, 2007), pp. 17-21, 348-49, and p. 412.

${ }^{24}$ See Jonathan Dancy, Ethics Without Principles (Oxford, 2004), chs. 2 and 3.

${ }^{25}$ Ethics Without Principles, p. 45.

26 See also Andrew Mason, 'Egalitarianism and the Levelling Down Objection', Analysis 61 (2001), pp. $246-54$, at p. 249.
} 
tion in this context, then let us assume that I have all things considered reason to do $X$. But now suppose we find out that I was under severe duress while making the promise because someone else held a gun to my head. If I did not make the promise freely, then it is not the case anymore that I have overall reason to do $X$. The favourer of promising to do $X$ requires the enabler of not having given the promise under duress.

Although this line of thought seems promising, it is not entirely convincing. Consider a modified version of Twin Trouble. Imagine that you must make a decision between two different options. If you choose option one, then both Anne and Betty will exist with moderate impairments. Alternatively, if you choose option two, then Charlie will exist with the very slight and Daisy with the very severe impairment. Suppose that regardless of which option you choose, the sum total of the well-being of the two people remains the same.

It seems that in this case an egalitarian would choose option one, because it will result in an equal distribution of well-being between Anne and Betty which will contain no intrinsically bad inequality. Yet we here seem to have moral reasons to choose option one although there are no claims on behalf of anyone. This is because, unlike in Twin Trouble where each individual has an equal chance of existence independent of our actions, our actions here will cause the existence of the individuals in question. ${ }^{27}$ In light of this counterexample, I therefore believe that it is unlikely that our reasons to act on inequality require the presence of an individual's claim as an enabler.

27 As this case also shows, the claims-based approach finds its limit in those non-identity cases, in which it is because of our actions that some individuals will exist as opposed to others. As Fleurbaey and Voorhoeve rightly note, if this problem cannot be overcome, then this means that the competing claims view can therefore only be 'one element' in a complete theory of distributive justice; see 'Egalitarianism and the Separateness of Persons', p. 398; and Otsuka, 'Prioritarianism and the Separateness of Persons', p. 372, n. 17. 


\subsection{Recasting the Competing Claims View}

There is a different, non-Temkinian way to modify the competing claims view that nonetheless allows it to capture Twin Trouble, remain invulnerable to the LDO, and keep its distinctness as an approach.

As we have seen previously, the claim egalitarian view, in line with Temkin, maintains that Chloe's claim is stronger than Anne's by appeal to the fact that she is unfairly worse off than Anne. It identifies such cosmically unfair inequalities as morally significant and thereby explains why they affect the strength of individuals' claims.

But a proponent of the competing claims view can accept that inequality matters, and (among other things) determines the strength of claims, without holding that this is because inequality is intrinsically bad.

Recall that on the competing claims view, we have stronger reason to satisfy claim over another simply by 'virtue of the fact that it is, other things equal, harder to justify improving the situation of someone who is better off rather than someone who is worse off.' 28 Such claims ground moral complaints on part of those individuals who are or would be worse off than others.

Otsuka and Voorhoeve can simply claim that the inequality between individuals with and without claims affects the strength of claims. As we saw earlier, in Twin Trouble, we can justify our decision to benefit Chloe to Anne in case she exists as follows: if Chloe existed, she would be worse off than Daisy even after having received the treatment for her disability. Yet in case we help Anne but Chloe existed, no such justification would be available. And the availability of this justification grounds a stronger moral complaint (and hence claim) on Chloe's behalf.

28 'Why It Matters', pp. 183-84, my emphasis. 
More generally, the rhetorical question to illustrate the competing claims complaint thus becomes: how could one justify giving a benefit to someone who, if she existed, would be already better off than others, when we could instead provide an equally large benefit to someone else who, if she existed, would still be worse off than others? Accordingly, on this

Modified Competing Claims View, the strength of individual's claim depends in part on her level of well-being relative to everyone else who exists alongside her.

But in contrast to the claim egalitarian view, the modified competing claims view does not maintain that it is because there is something intrinsically bad about the fact that some people are worse off than others through no choice or fault of theirs that an individual's claim can be stronger. It is because the presence of such inequality grounds stronger moral complaints.

To show that the competing claims complaint so conceived is in fact distinct from the egalitarian appeal to the intrinsic badness of unfair inequality, consider another modified version of Twin Trouble. Suppose that everything remains as in the original case except that this time none of the individuals involved have an independent chance of existing. Instead, imagine that you must choose between moving to the coast or the countryside and that this choice will make a difference to the identities of the individuals who will exist. If you choose to move to the coast, then Anne and Betty will exist and Anne will be able to receive the treatment for her moderate respiratory impairment. And if you choose to move to the countryside, then Chloe and Daisy will exist and Chloe will be able to receive the treatment for her respective impairment.

Given this slight modification, the egalitarian complaint against choosing to move to the coast would be just as strong as in the original version of the Twin Trouble case. The complaint would be that this choice would even further increase cosmically unfair inequality between Anne and Betty. We therefore have reason to choose to move to the countryside which will 
cause Chloe and Daisy to exist, thereby allowing Chloe to be benefitted. However, for the same reason that I gave in the previous subsection, we could not justify this choice by appeal to a competing claims complaint. There is no claim on behalf of Chloe because she does not have a claim to be brought into existence.

As regards the possibility of levelling down, note that the modified competing claims view does not face the problem of its claim egalitarian counterpart. Even if the presence of worse or better off individuals who will remain unaffected by our choices can affect the strength of an individual's claim (who will be affected), we still do not have even pro tanto moral reason to eliminate this inequality by making that individual worse off. Since the modified competing claims view is only triggered when an individual's interests are at stake, the possibility of making that individual worse off does not even arise. Hence this view does not invoke the intrinsic badness of inequality in the manner of an egalitarian such as Temkin. However, importantly, inequality still matters because it strengthens the claims of those who fare relatively worse off than others with and without claims.

\section{Conclusion}

Let us take stock. We have seen that restricted prioritarianism fails to register our conviction that we should move to the countryside to help Chloe and, more generally, certain types of morally significant justifications of arrangements to the individuals involved. We have also seen that a prioritarian defender's only option is to bite the bullet. Yet, this does not change the fact that restricted prioritarianism has to take a hit. On the other hand, we have seen that the modified competing claims view can correctly capture these types of justifications while providing a plausible explanation for why this does not commit us to levelling down (unlike the claim egalitarian view). 
At this point, we might therefore not only question the explanatory plausibility of restricted prioritarianism but also the necessity to endorse it altogether. As noted, Parfit argues that part of the motivation behind the non-relational prioritarian approach as well as part of its appeal lie in its invulnerability to the LDO ${ }^{29}$ But since the modified competing claims view escapes the LDO, we have no more reason to endorse restricted prioritarianism in the first place. It seems that the modified competing claims view indeed robs restricted prioritarianism in part of its raison d'être.

The foregoing discussion thus suggests a two-fold problem for the defender of restricted prioritarianism. First, the onus is now on her to demonstrate the plausibility of her view since it lacks the explanatory power of its relational counterpart; and second, she owes us an additional reason to endorse the view apart from its invulnerability to the LDO.

To conclude, I have attempted to the resolve the dispute between restricted prioritarianism and the competing claims view. I have argued that the modified competing claims view has greater plausibility than restricted prioritarianism and that it undermines part of the prioritarian's motivation to endorse restricted prioritarianism in the first place. For the prioritarian, the only way out of this is to bite the bullet. I therefore conclude that we have reason to reject restricted prioritarianism.

29 'Equality and Priority', p. 214. 


\section{References}

Arneson, Richard, 'Egalitarianism and Responsibility,' The Journal of Ethics 3 (1999), pp. 22547.

——, 'Primary Goods Reconsidered', Noûs (1990), pp. 429-454.

Cohen, G.A., 'On the Currency of Egalitarian Justice', Ethics 99 (1989), pp. 906-44.

Dancy, Jonathan, Ethics Without Principles (Oxford, 2004).

Hirose, Iwao, 'Aggregation and the Separateness of Persons', Utilitas 25 (2013), pp. 182-205.

Kamm, Frances, Intricate Ethics: Rights, Responsibilities, and Permissible Harm (Oxford, 2007).

Mason, Andrew, 'Egalitarianism and the Levelling Down Objection', Analysis 61 (2001), pp. 246-254.

Nagel, Thomas, 'Equality', Mortal Questions (Cambridge, 1979), reprinted in The Ideal of Equality, ed. Clayton and Williams (Basingstoke, 2002).

— Equality and Partiality (New York, 1991).

_ The Possibility of Altruism (Princeton, 1970).

Otsuka, Michael, and Voorhoeve, Alex, 'Why It Matters that Some Are Worse Off than Others: An Argument against the Priority View,' Philosophy and Public Affairs 37 (2009), pp. 171-199.

Otsuka, Michael, 'Prioritarianism and the Separateness of Persons', Utilitas 24 (2012), p. 372.

Parfit, Derek, 'Equality and Priority', Ratio 10 (1997), pp. 202-221.

Temkin, Larry S., 'Inequality: A Complex, Individualistic, and Comparative Notion', Philosophical Issues 11 (2001), pp. 327-53.

— , 'Equality, Priority, and the Levelling Down Objection', The Ideal of Equality, ed. Clayton and Williams (Basingstoke, 2002), pp. 126-61.

Fleurbaey, Marc, and Voorhoeve, Alex 'Egalitarianism and the Separateness of Persons', Utilitas, 24 (2012), pp. 381-398. 
Page 22 of 22

Williams, Andrew, 'The Priority View Bites the Dust?', Utilitas 24 (2012), pp. 315-331.

Voorhoeve, Alex, 'How Should We Aggregate Competing Claims?', Ethics (2014), pp. 64-87. 